\title{
What is the optimal protocol for Intrauterine Insemination (IUI)? A Mini Review and A Retrospective Study to Evaluate Effective Factors Influencing Pregnancy after IUI
}

\section{Qing Li ( $\sim$ qingli_sz@163.com )}

Birmingham Women's and Children's NHS Foundation Trust https://orcid.org/0000-0001-9134-6071

\section{Belén Herrero}

Royal Victoria Hospital

Mao-Ling Zhu

Nanning Maternal and Child Health Care Hospital

Josée Lefebvre

Newcastle upon Tyne Hospitals Department of Laboratory Medicine

William Buckett

Royal Victoria Hospital

\section{Research}

Keywords: infertility, intrauterine insemination, effective factors, clinical pregnancy rate.

Posted Date: December 9th, 2019

DOI: https://doi.org/10.21203/rs.2.18510/v1

License: (c) (i) This work is licensed under a Creative Commons Attribution 4.0 International License.

Read Full License 


\section{Abstract}

Background: Although it is well documented on the study of intrauterine insemination (IUI), the effectiveness of various factors on IUI treatment is inconsistent. The aim of this study is to investigate the various factors that influence IUI outcome and attempt to set up optimal protocol for IUI patients. Methods: This was a retrospective cohort study including1948 cycles (843 couples) that performed IUI between January 2012 and December 2013 in a single centre. Various factors that may affect IUI outcome were analyzed using chi-square. Moreover, we conducted multiple logistic regression to evaluate the main factors on the effects of IUI outcome. In addition, follicle growth and endometrial development relevant to conception were also assessed among protocols. Results: The clinical pregnancy rate (CPR) per cycle was $12.5 \%$ in the present study. Seven factors were identified to be associated significantly with CPR by multivariate logistic regression analysis: female age, type of infertility, ovarian stimulation protocol, preovulatory follicles, endometrial thickness, growing length of preovulatory follicle, post-washed total motile spermatozoa count (TMSC). Comparing with 11 days or less, more than 15 days for ovarian response and endometrial development before insemination induced a better success rate. Although ovarian stimulation with gonadotrophin or letrozole induced higher CPR when comparing to stimulation with clomiphene citrate or without stimulation, ovarian stimulation with letrozole was superior to gonadotrophin by its similar CPR to gonadotrophin but lower follicle number, without the risk of multiple pregnancy. Women younger than 41 years with elevated endometrial thickness inseminated with TMSC $\geq 4.0$ million had better chance to obtain pregnancy. Number of treatment cycle was not a factor to affect CPR, with a stable CPR in the first four cycles. Conclusions: We conclude that women no more than 41 years old are suitable to perform at least 4 cycles of IUI before proceeding to IVF. The optimized IUI treatment requires ovarian stimulation with letrozole to induce one/two follicles and fertilize with four or more million motile spermatozoa and an elevated endometrium on day 15 or after in the cycle. Key words: infertility, intrauterine insemination, effective factors, clinical pregnancy rate.

\section{Introduction}

Intrauterine insemination (IUI) with or without mild ovarian stimulation is commonly used as first line treatment to those couples who are diagnosed as cervical infertility, anovulation, male subfertility or unexplained infertility because it is simple, noninvasive and less expensive with reasonable cumulative live birth rate [1]. IUI provides a more patient-friendly strategy compared to more sophisticated in vitro fertilization (IVF) treatments.

Many studies on IUI have been reported. As we know, age is the most important variable that effects IUI outcome [2,3]. However it is not clear at which age patients should be transferred to IVF directly in order to save time and energy for advanced age women. Controlled ovarian hyperstimulation $(\mathrm{COH})$ with gonadotrophin or clomiphene citrate (CC) are commonly applied by physicians in the treatment of IUI, but the effectiveness of letrozole is not well recognized $[4,5]$. The number of IUI attempts that should be offered varies strongly [6, 7]. Other factors such as male age [8], basal follicle stimulation hormone (FSH) 
[9], estradiol $\left(\mathrm{E}_{2}\right)$ [10], antral follicle count (AFC) [11], type of infertility [12, 13], duration of infertility [6, 14], type of diagnosis $[13,15]$, follicle number $[15,16]$ and endometrial thickness [17] are well documented with inconsistent conclusions. Many aspects that could optimize IUI success rate remained to be defined.

In 2016 Quebec government proposed a drastic cut on IVF public funding, although unlimited cycles for IUI continued to be funded leading to a greater number of IUI cycles. The purpose of our study was to evaluate various variables that affected IUI success and to attempt setting up optimal protocol that could guide physicians at the time of counseling couples regarding their personalized IUI treatment plan.

\section{Materials And Methods}

A total of 1948 cycles (843 couples) that performed IUI between January 2012 and December 2013 in our center was included in this retrospective study. In order to review complete IUI treatment for a patient, some cycles performed before or after this period were also included. In general, women had undergone the following tests before treatment: hysterosalpingography and/or laparoscopy for assessment of tubal patency, ultrasound examination for AFC, and serum hormone assays for basal FSH, luteal hormone (LH), $E_{2}$ on day 3-5 of the menstrual cycle. Semen was analyzed guided by World Health Organization guidelines [18]. All patients in this study started IUI as their first-line treatment, thus IUI performed after IVF failure was excluded in the present study. Moreover, IUI converted from IVF due to no egg collected, donor sperm or frozen sperm insemination were excluded from the present study. This study has been received approval by the Research and Ethics Board of McGill University Health Center (study \#14-486SDR).

We carried out IUI for those patients who were diagnosed as anovulation (polycystic ovarian syndrome, according to the Rotterdam criteria) [19], diminished ovarian reserve (DOR), mild or moderate endometriosis, mild male subfertility, combined causes and unexplained infertility. Ovulation was induced by natural or by stimulation with CC, letrozole or gonadotrophins. Letrozole $(5 \mathrm{mg})$ or CC (50-150 mg) was taken daily for five days from day 3 of the cycle. Gonadotrophins (75-150 IU) were administered subcutaneously daily from day 3 of the cycle and adjusted the dose depending on the development of the follicles. Follicle scan was performed by transvaginal ultrasound examination on day 9-14 of the cycle with an interval of 2-3 days. Ovulation was triggered when one or more preovulatory follicle reached $17 \mathrm{~mm}$. Semen was collected by masturbation and prepared with two layers of density gradients ( $40 \%$ and $80 \%$ ) and then washed with non-capacitating buffer. A single insemination of $0.5 \mathrm{ml}$ sperm suspension was carried out 24 or 36 hours after triggering. No luteal support was prescribed. When there were more than three follicles, we recommended patients to cancel IUI or switch to IVF. Insemination was performed only if patients insisted after being fully informed the risk of multiple pregnancies. The presence of a gestational sac was taken as clinical pregnancy.

In this study the main outcome was clinical pregnancy rate (CPR). Demography data were recorded including maternal age, paternal age, duration of infertility, type of infertility, diagnosis of infertility, basal levels of FSH and $E_{2}$, and AFC. Characteristics of individual cycles were also collected including the 
protocol of ovarian stimulation, attempt number of IUI, duration between triggering and insemination, growing length of preovulatory follicle, total motile spermatozoa count (TMSC) after washing, preovulatory follicle number and endometrial thickness on the triggering day.

\section{Statistical analysis}

We used SPSS 17 (Chicago, IL) for data analysis. Results were expressed as mean \pm SD. T-test, ANOVA or Kruskal Wallis H Test were used for comparing the means of variables when appropriated. Chi-square was used for analysis of categorical variables. $P$ value $<0.05$ was considered statistically significant. Multivariate logistic regression with backwards selection was taken to evaluate the associations between the occurrence of pregnancy and the variables. All variables that reached $30 \%$ of significant level by chisquare test were analyzed by multivariate logistic regression with backwards selection [13]. Odds ratios (OR) and 95\% confidence interval (95\% Cls) constituted the description analysis.

\section{Results}

A total of 1948 homologous IUI cycles led to 244 clinical pregnancies (12.5\%), in which 2 cases of ectopic pregnancies $(0.8 \%)$ and 33 cases miscarriages $(13.5 \%)$ occurred during the first trimester. Among the pregnancies, 24 cases (9.8\%) were twin, 3 cases (1.2\%) triplet. The CPR per couple was $28.9 \%$.

Each couple was taken $2.31 \pm 1.15 \mathrm{IUI}$ cycles on average. As shown in Fig. 1, CPRs were 10.9\%, 11.8\%, $16.0 \%, 15.0 \%, 20.6 \%$ and $12.5 \%$ for the 1 st to the 6 th cycle, respectively and no significant differences were found between these groups. The cumulative clinical pregnancy rates (CCPR) were $26.0 \%$ after 3 attempts and $28.9 \%$ after 6 attempts.

Maternal age and paternal age at the time of the first IUI cycle were $33.19 \pm 4.42$ and $36.48 \pm 5.72$ years old. Causes of infertility were as follows: female factor $33.6 \%$, male factor $13.5 \%$, combined causes $11.2 \%$ and unexplained infertility $41.8 \%$ of cases. In our study, female factors included anovulation (65.7\%), DOR (18.0\%), endometriosis (5.7\%) and fallopian tube anomalies (10.6\%). Primary infertility was described in $57.2 \%$ of the women and the remaining $42.8 \%$ had secondary infertility. Mean infertility duration was $2.17 \pm 1.62$ years.

In Table 1, clinical pregnancy outcomes were analyzed by chi-square test. Female age significantly influenced CPR and no conception occurred when women reached 42 years old. Although there was a decreasing trend in CPR with increased age, no significant difference was found among the groups when women were younger than 42 years old $(P=0.088)$. Similarly, $C P R$ was not significantly affected by male age. Type of infertility but not diagnosis of infertility was significantly associated with CPR $(10.8 \%$ primary versus $15.0 \%$ secondary; $P<0.05$ ). Interestingly, when female factor was divided into 4 categories (anovulation, DOR, tubal factor and endometriosis), women diagnosed with anovulation showed significantly higher CPR than those diagnosed with DOR or tubal factors $(18.6 \%, 8.8 \%, 4.1 \%$; respectively; $P<0.01)$. 
Table 1

Relationship between patients' characteristics and IUI clinical pregnancy.

\begin{tabular}{|c|c|c|c|c|}
\hline Characteristics & No. of cycles, $n$ & Clinical pregnancy, n(\%) & $x^{2}$ & P Value \\
\hline \multicolumn{5}{|l|}{ Female age (yrs) } \\
\hline \multirow{5}{*}{$\begin{array}{l}\leq 29 \\
30-34 \\
35-39 \\
40-41 \\
\geq 42\end{array}$} & 378 & $58(15.3 \%)$ & 10.998 & .027 \\
\hline & 764 & $104(13.6 \%)$ & & \\
\hline & 681 & $70(10.3 \%)$ & & \\
\hline & 95 & $12(12.6 \%)$ & & \\
\hline & 30 & $0(0.0 \%)$ & & \\
\hline \multicolumn{5}{|l|}{ Male age } \\
\hline \multirow{5}{*}{$\begin{array}{l}\leq 29 \\
30-34 \\
35-39 \\
40-41 \\
\geq 42\end{array}$} & 139 & $23(16.5 \%)$ & 6.665 & .155 \\
\hline & 648 & $87(13.4 \%)$ & & \\
\hline & 640 & $83(13.0 \%)$ & & \\
\hline & 150 & $17(11.3 \%)$ & & \\
\hline & 371 & $34(9.2 \%)$ & & \\
\hline \multicolumn{5}{|c|}{ Types of infertility } \\
\hline \multirow{2}{*}{$\begin{array}{l}\text { Primary } \\
\text { Secondary }\end{array}$} & 1142 & $123(10.8 \%)$ & 7.760 & .005 \\
\hline & 806 & $121(15.0 \%)$ & & \\
\hline \multicolumn{5}{|c|}{ Diagnosis of infertility } \\
\hline \multirow{8}{*}{$\begin{array}{l}\text { Female factor } \\
\text { Male factor } \\
\text { Combined } \\
\text { Unexplained } \\
\text { Female factors } \\
\text { Anovulation } \\
\text { DOR } \\
\text { Endometriosis } \\
\text { Tubal }\end{array}$} & 633 & $93(14.7 \%)$ & 7.080 & .069 \\
\hline & 264 & $25(9.5 \%)$ & & \\
\hline & 210 & $31(14.8 \%)$ & & \\
\hline & 841 & $95(11.3 \%)$ & & \\
\hline & 419 & $78(18.6 \%)$ & 16.032 & .001 \\
\hline & 102 & $9(8.8 \%)$ & & \\
\hline & 38 & $3(7.9 \%)$ & & \\
\hline & 74 & $3(4.1 \%)$ & & \\
\hline
\end{tabular}


Ovarian function was evaluated based on the serum concentration of $\mathrm{FSH}, \mathrm{E}_{2}$ and $\mathrm{AFC}$. We analyzed these three factors separately by chi-square with data available in 1902 cycles for $F S H, 1833$ cycles for $E_{2}$ and 1914 cycles for AFC. We observed statistically significant higher CPR in patients with FSH level $\leq$ $10 \mathrm{IU} / \mathrm{L}$ than those more than $10 \mathrm{IU} / \mathrm{L}(12.9 \%$ versus $7.1 \%, \mathrm{P}<0.05)$. However, no statistical significance was found with $\mathrm{E}_{2}$ level above or below $80 \mathrm{pg} / \mathrm{ml}(12.8 \%$ versus $12.5 \%, \mathrm{P}>0.05)$. Regarding AFC, CPR was significantly higher when AFC was more than 7 compared to below $7(13.1 \%$ versus $8.3 \%, P<0.05)$.

Out of 1948 cycles, the majority of the cycles $(1262,64.8 \%)$ was stimulated with FSH or/and LH, whereas the others were stimulated with CC $(550,28.2 \%)$, letrozole $(67,3.4 \%)$ or without stimulation $(61,3.1 \%)$. Eight $(0.4 \%)$ cycles were treated with gonadotrophins following CC due to no response on the ovaries to CC. As showed in Table 2, higher CPRs were observed in the groups treated with gonadotrophin (13.9\%) or letrozole $(17.9 \%)$ than with CC $(9.5 \%)$ or no treatment $(4.9 \%)$. In the cycles treated with gonadotrophin, the mean of the total dose used was $710.1 \pm 533.0 \mathrm{IU}$, and the length of treatment was $13.9 \pm 3.6$ days. Inseminations were carried out mainly on day 12th of the cycle or after. Higher CPR was observed when inseminations were performed after day 15 th of the cycle compared to those on day 11 th $(15.0 \%$ versus $9.5 \% ; \mathrm{P}<0.05)$. However, no significant differences in CPR were observed when insemination was performed 24 or 36 hours after triggering (12.1\% versus $12.8 \%, P>0.05)$.

Cycles with two follicles had better CPR compared to cycles with one follicle (15.7\% versus $11.2 \%, \mathrm{P}<$ $0.05)$, although the risk of multiple pregnancy increased $(16.5 \%$ versus $6.5 \% ; P<0.05)$. For those cycles with three follicles, CPR did not improve but the risk of multiple pregnancy increased $(19.0 \%$ versus $6.5 \%$, $P=0.05)$. Moreover, CPRs significantly increased with the endometrial thickness $(6.3 \%, 13.0 \%$ and $26.8 \%$ for $<6 \mathrm{~mm}, 6-14 \mathrm{~mm}$ and $>14 \mathrm{~mm}$, respectively, $\mathrm{P}<0.01$ ).

Total motile sperm count significantly affect IUI outcome. No pregnancy occurred when TMSC was lower than 1.5 million and more than 10 million TMSC did not improve pregnancy outcome. 
Table 2

Effect of various IUI cycle parameters on clinical pregnancies

\begin{tabular}{|c|c|c|c|c|}
\hline Parameters & No. of cycles, $n$ & Clinical pregnancy, n(\%) & $x^{2}$ & P Value \\
\hline \multicolumn{5}{|c|}{ Ovarian stimulation protocol } \\
\hline \multirow{5}{*}{$\begin{array}{l}\text { Natural cycle } \\
\text { CC } \\
\text { Gonadotrophin } \\
\text { Letrozole } \\
\text { CC + Gonadotrophin }\end{array}$} & 61 & $3(4.9 \%)$ & 12.054 & .017 \\
\hline & 550 & $52(9.5 \%)$ & & \\
\hline & 1262 & $176(13.9 \%)$ & & \\
\hline & 67 & $12(17.9 \%)$ & & \\
\hline & 8 & $1(12.5 \%)$ & & \\
\hline \multicolumn{5}{|c|}{ Growing length of preovulatory follicle (days) } \\
\hline \multirow{3}{*}{$\begin{array}{l}<12 \\
12-14 \\
>14\end{array}$} & 380 & $36(9.5 \%)$ & 7.598 & .022 \\
\hline & 862 & $102(11.8 \%)$ & & \\
\hline & 706 & $106(15.0 \%)$ & & \\
\hline \multicolumn{5}{|c|}{ Duration between triggering to IUI (hours) } \\
\hline \multirow{2}{*}{$\begin{array}{l}24 \\
36\end{array}$} & 643 & $78(12.1 \%)$ & .137 & .712 \\
\hline & 1305 & $166(12.7 \%)$ & & \\
\hline \multicolumn{5}{|c|}{ Preovulatory follicle number } \\
\hline \multirow{4}{*}{$\begin{array}{l}0 \\
1 \\
2 \\
\geq 3\end{array}$} & 8 & $0(0.0 \%)$ & 7.973 & .047 \\
\hline & 1232 & $138(11.2 \%)$ & & \\
\hline & 543 & $85(15.7 \%)$ & & \\
\hline & 165 & $21(12.7 \%)$ & & \\
\hline \multicolumn{5}{|c|}{ Preovulatory follicle number in pregnancy cycles } \\
\hline \multirow{3}{*}{$\begin{array}{l}1 \\
2 \\
\geq 3\end{array}$} & 138 & $9(6.5 \%)^{a}$ & 6.778 & .034 \\
\hline & 85 & $14(16.5 \%)^{a}$ & & \\
\hline & 21 & $4(19.0 \%)^{a}$ & & \\
\hline \multicolumn{5}{|c|}{ Endometrial thickness (mm) } \\
\hline $\begin{array}{l}<6 \\
6-14\end{array}$ & 221 & $14(6.3 \%)$ & 15.717 & .000 \\
\hline$>14$ & & & & \\
\hline a & 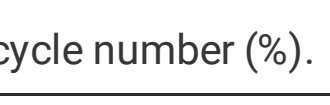 & & & \\
\hline
\end{tabular}




\begin{tabular}{|c|c|c|c|c|}
\hline Parameters & No. of cycles, $n$ & Clinical pregnancy, $n(\%)$ & $x^{2}$ & P Value \\
\hline & 1686 & $219(13.0 \%)$ & & \\
\hline & 41 & $11(26.8 \%)$ & & \\
\hline \multicolumn{5}{|c|}{ Post-washed TMSC (million) } \\
\hline \multirow{4}{*}{$\begin{array}{l}<1.5 \\
1.5-3.9 \\
4.0-9.9 \\
\geq 10.0\end{array}$} & 57 & $0(0.0 \%)$ & 13.200 & .004 \\
\hline & 91 & $5(5.5 \%)$ & & \\
\hline & 311 & $41(13.2 \%)$ & & \\
\hline & 1489 & 198(13.3\%) & & \\
\hline
\end{tabular}

As showed in Table 3, the effect of endometrial thickness on CPR was different between cycles treated with $\mathrm{CC}$ and with gonadotrophin. In the gonadotrophin group, the best CPR $(36.7 \%)$ was achieved when endometrial thickness was higher than $14 \mathrm{~mm}$. In contrast, the best CPR (11.2\%) was obtained in the CC group when endometrial thickness was between 6-14 mm. No conception was observed with endometrial thickness more than $14 \mathrm{~mm}$.

Table 3

Comparison of endometrial thickness on CPRs between women treated with CC and Gonadotrophins

\begin{tabular}{|c|c|c|c|c|}
\hline \multirow{3}{*}{$\begin{array}{l}\text { Endometrial thickness } \\
(\mathrm{mm})\end{array}$} & \multicolumn{4}{|c|}{ Ovarian stimulation } \\
\hline & \multicolumn{2}{|c|}{$C C(N=550)$} & \multicolumn{2}{|c|}{ Gonadotrophin $(N=1262)$} \\
\hline & $\begin{array}{l}\text { No. of } \\
\text { cycles }\end{array}$ & $\begin{array}{l}\text { Clinical pregnancies } \\
\mathrm{n}(\%)\end{array}$ & $\begin{array}{l}\text { No. of } \\
\text { cycles }\end{array}$ & $\begin{array}{l}\text { Clinical pregnancies } \\
\mathrm{n}(\%)\end{array}$ \\
\hline$<6$ & 120 & $5(4.2 \%)^{a}$ & 76 & $8(10.5 \%)^{c}$ \\
\hline $6-14$ & 420 & $47(11.2 \%)^{b}$ & 1156 & $157(13.6 \%)^{c}$ \\
\hline$>14$ & 10 & $0(0 \%)$ & 30 & $11(36.7 \%)^{d}$ \\
\hline$P$ value & & .040 & & .001 \\
\hline
\end{tabular}

The ovarian stimulation protocol significantly affected follicle recruitment, endometrial growth and then influenced the decision of the day of insemination (showed in Table 4). Compared to natural cycles, ovarian stimulation with CC significantly increased follicle number $(1.5 \pm 0.8$ versus $1.2 \pm 0.5, P<0.01)$, shortened one day readiness for insemination $(12.8 \pm 2.7$ versus $14.0 \pm 3.0, P<0.01)$, whereas stimulation 
with gonadotrophin not only increased follicle number ( $1.5 \pm 0.7$ versus $1.2 \pm 0.5, \mathrm{P}<0.01)$, but also thickened endometrium $(9.0 \pm 2.2$ versus $8.1 \pm 2.0, P<0.01)$ with similar days $(14.8 \pm 3.8$ versus $14.0 \pm 3.0$, $P>0.05)$ readiness for insemination. However, ovarian stimulation with letrozole prolonged two days $(16.2 \pm 4.6$ versus $14.0 \pm 3.0, P<0.01)$ readiness for insemination without increasing follicle number or endometrial thickness compared with natural cycles.

Table 4

Relationships between ovarian stimulation and follicle number, endometrial thickness and growing length of preovulatory follicle.

\begin{tabular}{|c|c|c|c|c|c|}
\hline Ovarian stimulation & $\begin{array}{l}\text { Natural } \\
\text { Cycle } \\
(n=61)\end{array}$ & $\begin{array}{l}C C \\
(n= \\
550)\end{array}$ & $\begin{array}{l}\text { Gonadotrophin } \\
(n=1262)\end{array}$ & $\begin{array}{l}\text { Letrozole } \\
(n=68)\end{array}$ & $\begin{array}{l}P \\
\text { Value }\end{array}$ \\
\hline Follicle number & $1.2 \pm 0.5^{\mathrm{a}}$ & $\begin{array}{l}1.5^{ \pm} \\
0.8^{\mathrm{b}}\end{array}$ & $1.5 \pm 0.7^{b}$ & $\begin{array}{l}1.3 \pm \\
0.6^{\mathrm{ab}}\end{array}$ & .001 \\
\hline Endometrial thickness (mm) & $8.1 \pm 2.0^{\mathrm{a}}$ & $\begin{array}{l}7.9 \pm \\
2.5^{\mathrm{a}}\end{array}$ & $9.0 \pm 2.2^{b}$ & $\begin{array}{l}7.5 \pm \\
2.2^{\mathrm{a}}\end{array}$ & .000 \\
\hline $\begin{array}{l}\text { Growing length of preovulatory } \\
\text { follicle (days) }\end{array}$ & $\begin{array}{l}14.0 \pm \\
3.0^{\mathrm{a}}\end{array}$ & $\begin{array}{l}12.8 \pm \\
2.7^{\mathrm{b}}\end{array}$ & $14.8 \pm 3.8^{a}$ & $\begin{array}{l}16.2 \pm \\
4.6^{c}\end{array}$ & .000 \\
\hline
\end{tabular}

Table 5

Factors associated with clinical pregnancy analyzed by multivariate logistic regression.

\begin{tabular}{|lccl|}
\hline Factors & OR & $95 \% \mathrm{Cl}$ & P Value \\
\hline Female age & 1.25 & $1.05-1.48$ & .011 \\
\hline Type of Infertility & .71 & $0.54-0.94$ & .017 \\
\hline Post-washed TMSC & .71 & $0.55-0.91$ & .008 \\
\hline Stimulation protocol & .69 & $0.54-0.88$ & .003 \\
\hline Growing length of preovulatory follicles & .79 & $0.64-0.97$ & .022 \\
\hline Number of preovulatory follicles & .79 & $0.64-0.98$ & .030 \\
\hline Endometrial thickness & .51 & $0.33-0.81$ & .004 \\
\hline Constant & 360.16 & & .000 \\
\hline OR: Odds ratio; Cl: Confidence interval. & & & \\
\hline
\end{tabular}


Table 5 depicts seven factors that were significantly associated to CPR: female age, type of infertility, post-washed TMSC, stimulation protocol, growing length of preovulatory follicle, preovulatory follicle number and endometrial thickness.

\section{Discussion}

In our centre, IUI is suggested as first-line treatment to infertile couples with anovulation, male subfertility, mild endometriosis or unexplained cause. In the majority of the cases $(96.9 \%)$, an ovarian stimulation protocol was the preferred choice. Overall, a 12.5\% pregnancy rate per cycle was recorded after IUI treatment. Since many factors influence IUI success, the purpose of this research was to find out predictive variables to achieve pregnancy.

\section{Pre-therapeutic factors}

Female age limit for IUI: Female age is commonly accepted to be negatively associated with success rate after IUI treatment $[2,3,6,13]$. A recent study including 178300 natural IUI cycles illustrated a clear agedependent relationship: pregnancy rates were $8.2 \%, 7.3 \%, 5.5 \%, 3.6 \%$ and $0.9 \%$ in women with $<35,35-37$, $38-40,41-42$ and $>42$ years of age respectively [20]. And this age-dependent relationship to CPR was also confirmed by our study. However, in the present study we are interested in the age limit that still benefit from IUI treatment. Several studies had described a low chance of pregnancy with IUI treatment in advanced age women. Nuojua-Huttunen et al. [6] reported that only $4.1 \%$ pregnancy rate per cycle in women older than 40 , suggesting that IUI was not beneficial for these women. This conclusion was supported by Wiser et al. who showed that IVF was most effective ( $16.9 \%$ of CPR) for women 40 years old or older compared to IUI cycles stimulated by gonadotrophin ( $2.6 \%$ of CPR) or by CC (no clinical pregnancy) [21]. In a large size study (4100 cycles), Dovey et al. classified women over the age of 40 into two groups: those women of 41-42 years old with a cumulative pregnancy rates per patient of $7.4 \%$ and women over 42 with a CPR per patient of $1.8 \%$, suggesting that there was still place to treat patients between 41-42 but not patients over 42 [22]. In a study of $1117 \mathrm{IUI}$ cycles, Haebe et al. also demonstrated that IUI was an appropriate treatment for women 40-42 years with 9.8\% CPR per insemination [23]. Likewise, in our study a CPR of $12.6 \%$ per cycle was achieved in women aged $40-41$ but no pregnancy obtained for women $\geq 42$. Based on our data, we considered IUI as a first line treatment for those women younger than 42 years old.

Basal $E_{2}, F S H$ and AFC levels: Basal hormone ( $E_{2}$ and $\left.F S H\right)$ assays and $A F C$ measured by ultrasound on day 2 or 3 of the cycle were used to evaluate ovarian reserve. Regarding basal $E_{2}$ level, no difference in pregnancy rate was observed whether $\mathrm{E}_{2}$ level was above or below $80 \mathrm{pg} / \mathrm{ml}(12.8 \%$ versus $12.5 \%, P>$ 0.05), supporting the study by Merviel et al. [3]. However, elevated basal $E_{2}(>80 \mathrm{pg} / \mathrm{mL})$ in advanced age women (38-42 years old) implied failure of obtaining conception even if basal FSH was normal [10]. In 
terms of basal FSH, the majority of the investigations described that an elevated FSH is negatively associated with pregnancy rate, although no defined cut-off value was applied. Magarelli et al. [24] suggested basal FSH (cut-off value of $23 \mathrm{IU} / \mathrm{L}$ ) was a significant predictor of pregnancies in patients over 35 years of age undergoing ovulation induction with IUI therapy. In a large prospective cohort study (3519 couples from 19 fertility centers), van der Steeg et al. [25] reported FSH levels $8 \mathrm{IU} / \mathrm{L}$ or greater were a strong negative predictor for spontaneous ongoing pregnancy. Similarly, our results showed that the chance of pregnancy in patients with basal FSH above $10 \mathrm{IU} / \mathrm{L}$ significantly decreased compared to those patients below this threshold $(7.1 \%$ versus $12.9 \%, P<0.05)$. The negative effect of high FSH on CPR might be caused by female age since elevated FSH was correlated with increasing women's age [26]. For those younger women, an elevated day $3 \mathrm{FSH}(\geq 10 \mathrm{U} / \mathrm{L}$ ) did not show harmful effects on reproductive outcomes in $\mathrm{COH} / \mathrm{IUI}$ cycles [27]. Regarding AFC, by their prospective study on the relationship of AFC to CPR, Erdem et al. proposed a cut-off value of 7.5 AFC to predict clinical pregnancy and live birth [11]. Our study showed that a lower chance for pregnancy occurred in patients with AFC below a cut-off value of 7 (8.3\% versus $13.1 \%, P \leq 0.05$ ). Both FSH and AFC can be correlated negatively with female age [26]. Recently, Fleming et al. [28] suggested that AFC, as well as anti-Müllerian hormone, were a good marker that evaluate ovarian reserve.

Type of infertility (primary and secondary): it is often one of the variables that can affect IUI outcome. In our study, we observed a significantly higher CPR in patients with secondary infertility than with primary infertility. Our finding was similar to the one described by Atasever et al. [12], that showed 1.84-fold increase in CPR in patients with secondary infertility than with primary infertility. On the contrary, some studies did not find difference between these two groups $[3,13,14]$. Unlike other studies $[6,14]$, duration of infertility did not seem to affect CPR in our research which is in agreement with the study by Merviel et al. [3].

\section{Diagnosis and its treatment factors}

Female factors: Several studies have shown that pregnancy was relatively easy to achieve once ovulation occurred by ovarian stimulation in infertile patients with anovulation $[3,15]$. Similarly our study showed that patients with anovulation (18.6\%) had better CPR per cycle than those with DOR, endometriosis or tubal factor. Endometriosis is considered to be one of the most difficult diagnoses to conceive successfully $[3,6,13]$. Allaire [29] described that patients with minimal and mild endometriosis could benefit from using CC or gonadotrophins with IUI. In our study only a 7.9\% CPR per cycle in patients with endometriosis was observed.

Unexplained factor: In our center, $43.2 \%$ of patients were diagnosed with unexplained infertility with a CPR of $11.3 \%$ per cycle. Based on data from 7 randomised controlled trials (RCTs), Hughes et al. [30] described similar live birth and clinical pregnancy rate per woman in IUI treatment with CC or placebo for 
unexplained subfertility. However, letrozole $(2.5 \mathrm{mg})$ displayed a statistically significantly higher CPR in couples with unexplained infertility than CC $(100 \mathrm{mg})$ [31]. In our study CC and letrozole showed similar effects on CPR in unexplained infertility couples. Recently Veltman-Verhulst et al. [32] reviewed 14 RCTs with 1867 unexplained infertility women where only four of them showed a higher live birth rate in women treated with IUI in a stimulated cycle than those with IUI in natural cycle. Due to the limited effect of IUI on success rate for unexplained infertility, the authors recommended that after 3 failed IUI ovarian stimulation cycles, treatment with IVF should be offered [33].

Male factor. There is no conflicting data regarding the positive association between TMSC and pregnancy outcome $[14,34,35]$. However, the question remains on what is the threshold value required for a good pregnancy outcome after IUI treatment. According to a review by Ombelet et al. [36], the cut-off value after sperm washing was between 0.8-5 million. However, some investigators claimed that a minimum threshold of 4-5 million TMSC is necessary to obtain optimal pregnancy rates per couple or per cycle $[2,3,35,37]$, whereas other investigators $[34,38,39]$ proposed a higher cut-off value of 10 million TMSC. A large size study (3417 cycles) by Van Voorhis et al. [38] showed that 10 million TMSC is necessary to achieve pregnancy. In the present study we report an optimal threshold of 1.5-4 million TMSC. A higher number of spermatozoa than 4 millions did not improve IUI outcome. If this threshold of TMSC after preparation cannot be obtained, IVF should be recommended.

What is the best treatment for male mild subfertility? A Cochrane systematic review on male subfertility by Cissen et al. [40] found similar pregnancy or live birth rates between IUI treatment and timed intercourse with or without ovarian stimulation. An RCT described by Bensdorp et al. [41] revealed that $\mathrm{IUI} / \mathrm{COH}$ induced comparable live birth rate to IVF in modified natural cycles or IVF with single embryo transfer. Goverde et al. [42] considered IUI should be the first choice of treatment in couples with male subfertility since IUI was more cost-effective than IVF.

\section{Cycle relevant factors}

Ovarian stimulation: Clomiphene citrate or gonadotrophins is commonly used as an attempt to induce ovulation. Although CC with IUI in ovulatory couples show more effective than timed intercourse in natural cycles, ovarian stimulation with gonadotrophins is reported superior than CC [1, 4, 43, 44]. Similarly, our results showed significantly higher CPR for women stimulated with gonadotrophins than those stimulated with CC $(13.9 \%$ versus $9.5 \%, P<0.05)$. In recent years aromatase inhibitor such as letrozole was also used as a method for ovarian stimulation because of its function to block the conversion of androgen to $E_{2}$. In anovulation infertility, two reviews with large RCTs drew a firm conclusion that letrozole induced significantly higher pregnancy and live birth rates when compared to CC $[45,46]$. However, its effectiveness on other infertilities after IUI was not clarified. In our study, letrozole was superior to CC in terms of CPR $(17.9 \%$ versus $9.5 \%, P<0.05)$, which was supported by a small RCT that showed letrozole created higher CPR than CC [47]. 
Follicle number: It is accepted that ovarian stimulation with more preovulatory follicles would lead to a better reproductive outcome. For instance, Park et al. [15] reported that the live birth rate increased from $6.8 \%$ to $10.5 \%$ as the number of large follicles increased from one to two. Moreover, other studies described that if the number of follicles increased from one to three, the IUI success rate was 2-3 times higher $[6,14,48]$. In our study, it was observed that the recruitment of two preovulatory follicles (> $16 \mathrm{~mm})$ significantly increased CPR compared with one follicle after IUI $(15.7 \%$ versus $11.2 \%, P<0.05)$. The recruitment of more than 2 follicles did not improve pregnancy rate but adversely increased multiple pregnancy rate [16]. We agreed with van Rumste et al. [16] who proposed that one stimulated follicle instead of two or more should be the goal for IUI treatment if safety is primarily concerned.

Endometrial thickness: The association between the thickness of endometrium and pregnancy is well documented. In IVF cycle a fresh embryo should not be transferred if the thickness of endometrium is $<5$ $\mathrm{mm}$ according to the National Institute for Health and Care Excellence fertility guideline [49]. However in IUI treatment the data on endometrial thickness is controversial. In a prospective study with ovarian stimulation (CC, HMG or combination of both), no pregnancies occurred when endometrial thickness was $<6 \mathrm{~mm}$, and $12.6 \%$ when endometrial thickness was $\geq 9 \mathrm{~mm}$ [50]. A recent large retrospective study (1065 cycles) by Liu et al. [51] revealed that there was a trend towards increasing CPRs with increasing endometrial thickness up to $14 \mathrm{~mm}$, beyond which pregnancy rates diminished. In contrast, in a review Weiss et al. [52] found no evidence between the thickness of endometrium and pregnancy rate during IUI with ovarian stimulation. In our study, we divided endometrial thickness into three groups: below $6 \mathrm{~mm}$, 6$14 \mathrm{~mm}$ and above $14 \mathrm{~mm}$ and we found CPRs increased significantly with the increasing of endometrial thickness $(6.3 \%, 13.0 \%, 26.8 \%$, respectively, $P<0.01)$. Interestingly, the association between endometrial thickness and pregnancy outcome varies between CC and gonadotrophin cycles. In CC cycles, no pregnancy was observed when endometrial thickness was more than $14 \mathrm{~mm}$, whereas in gonadotrophin cycles the best pregnancy rate was achieved in this group.

Timing of insemination: Insemination is considered to be carried out closely prior to ovulation since the success rate is significantly lower when IUI is carried out post ovulation [53]. In our study, we investigated the length of days before insemination (growing length of preovulatory follicle) as well as the duration between triggering (or LH surge) and insemination. We found that the growing length of preovulatory follicles was a factor that affect success rate after IUI. The likelihood of clinical pregnancies was higher significantly when insemination was carried out after day $15^{\text {th }}$ of the cycle than before day $11^{\text {th }}$ of the cycle $(15.0 \%$ versus $9.5 \% ; P<0.05)$. Regarding duration between triggering and insemination, we did not find significant difference in CPR inseminated between 24 and 36 hours after triggering or LH surge (12.1\% versus $12.7 \%, P>0.05)$. Our results are in accordance with three RCTs summarized by Cohlen et al. [33], where no significant differences in clinical pregnancy or live birth rate were found between various time frames of that ranged. 
Cycle number: How many cycles of $\mathrm{COH} / \mathrm{IUI}$ should be provided to patients before moving on to more effective and more expensive technology like IVF? In the literature, a range of 2-6 cycles was suggested by various investigators based on female age or diagnosis. Aboulghar et al. proposed that patients should be treated with IVF if no conception has happened after three trials of IUI with ovarian stimulation [54]. Some investigators such as Nuojua-Huttunen et al. selected a cut-off value of four cycles since they found that $97 \%$ of the pregnancies occurred in the first four IUI cycles [6]. Based on similar result Agarwal et al. advised that CC with IUI therapy should not extend beyond four cycles [55]. This suggestion was further confirmed by a large size of IUI study with $3381 \mathrm{CC}$ stimulated cycles in which pregnancy rates kept constant until four cycles then significantly dropped in the fifth or sixth cycles [48]. In respect to the optimized number of cycles of IUI upon various age, Agarwal et al. [55] observed the majority of pregnancies occurred within the first four IUI cycles, irrespective of age. However, Honda et al. [20] discovered that the trend of pregnancy rates relevant to cycle number was different according to female age: significantly higher in the first three cycles than in the 4th to 6th cycles or 7th to 9th cycles when women less than 40 years old but no difference was observed at the age over 41 years old. In contrast to the results above, in our study CPR remained stable from the first to the sixth cycle, which was supported by Merviel et al. [3]. Due to limit data in the fifth and the sixth cycle, we suggest that at least three or four trials of IUI should be provided to patients before considering IVF.

Thus, the question that arises is then what is the best protocol to a given patient? As we discussed above, ovarian stimulation with gonadotrophins or letrozole gives a higher chance for conception than stimulation with CC or without stimulation. Follicle number, endometrial thickness and growing length of preovulatory follicles are also factors that affect IUI success rate. Moreover, stimulation protocol interacts with follicle development, endometrial growth and therefore further influenced the decision of the day of insemination. Ovarian stimulation with CC significantly increased follicle number $(1.5 \pm 0.8$ versus $1.2 \pm$ $0.5, P<0.01)$ but shorten one day for insemination $(12.8 \pm 2.7$ versus $14.0 \pm 3.0, P<0.01)$ which might be harmed for full development of oocytes, therefore no advantage in CPR was observed over natural cycle. Ovarian stimulation with gonadotrophins did increase CPR though increasing endometrial thickness (9.0 \pm 2.2 versus $8.1 \pm 2.0, P<0.01)$ and follicle number $(1.5 \pm 0.7$ versus $1.2 \pm 0.5, P<0.01)$, which might increase the risk of multiple pregnancies. Compared with natural cycle, ovarian stimulation with letrozole induced similar number of follicle $(1.3 \pm 0.6$ versus $1.2 \pm 0.5, P>0.05)$ and endometrial thickness $(7.5 \pm$ 2.2 versus $8.1 \pm 2.0, P>0.05)$, on the other hand it allowed follicles to grow two more days $(16.2 \pm 4.6$ versus $14.0 \pm 3.0, P<0.05$ ), which may be benefit for oocyte maturation that led to a higher success rate after IUI without increasing the risk of multiple pregnancies; thus we considered letrozole the ovarian stimulation protocol for best IUI conception. To our knowledge, this is the first study to date evaluating ovarian stimulation protocol by comparing their CPRs, as well as follicle number, growing length of preovulatory follicles and endometrial thickness. More investigation with randomized controlled trial in the future will be necessary to confirm this idea. 
The main strength in this study is the large number of cases evaluated, although we acknowledged its retrospective nature as a limitation. In an effort to reveal the most important variables that significantly influence IUI outcome, a multivariate logistic regression analysis was performed. Seven factors were identified: female age, type of infertility, ovarian stimulation protocol, preovulatory follicles number, endometrial thickness, post-washed TMSC and growing length of preovulatory follicle; the latter rarely being described in the literature. Type of diagnosis and duration of infertility, basal FSH and $\mathrm{E}_{2}$ levels, AFC, duration between triggering and IUI, and male age had no predictive values on IUI outcome.

\section{Conclusion}

In conclusion, our data supports the concept that IUI treatment is effective for those couples with secondary infertility, being the female partner no more than 41 years old and male partner with a TMSC of more than four million. The use of letrozole therapy with appropriate endometrial thickness gives a higher pregnancy rate without the risk of multiple pregnancy. We recommend that at least four IUI attempts should be considered before shifting to IVF. The use of the current data may help clinicians in the counseling of couples and the guidance in clinical decision making.

\section{Abbreviations}

IUI: intrauterine insemination; CPR: clinical pregnancy rate; TMSC: total motile spermatozoa count; CC: clomiphene citrate; $\mathrm{COH}$ : controlled ovarian hyperstimulation; IVF: in vitro fertilization; FSH: follicle stimulation hormone; $\mathrm{E}_{2}$ : estradiol; AFC: antral follicle count; LH: luteal hormone; DOR: diminished ovarian reserve; CCPR: cumulative clinical pregnancy rate; RCT: randomised controlled trial

\section{Declarations}

\section{Acknowledgements}

Not applicable.

\section{Funding}

Not applicable.

\section{Availability of data and materials}


The datasets used and/or analyzed during the current study are available from the corresponding author on reasonable request.

\section{Authors' contributions}

QL and BH substantial contributed to conception, study design, article drafting and critical revising of the manuscript. QL collected data and performed the statistical analysis. JL participated in interpretation of data. MLZ and WB contributed to conception and critically revised the manuscript. All authors gave the final approval of the manuscript.

\section{Ethics approval and consent to participate}

This study was approved by the Research and Ethics Board of McGill University Health Center (study \#14486-SDR).

\section{Consent for publication}

Not applicable.

\section{Competing interests}

The authors declare that they have no competing interests.

\section{Publisher's Note}

Springer Nature remains neutral with regard to jurisdictional claims in published maps and institutional affiliations.

\section{Author details}

${ }^{1}$ Nanning Maternal and Child Health Care Hospital, Nanning, China. ${ }^{2}$ McGill University Health Centre, Montreal, QC, Canada

\section{References}


1.

Cohlen BJ. Should we continue performing intrauterine inseminations in the year 2004? Gynecol. Obstet Invest. 2005;59:3-13.

2.

Stone BA, Vargyas JM, Ringler GE, Stein AL, Marrs RP, Bronte A, Stone PD, Ringler GE, Stein AL, Marrs RP. Determinants of the outcome of intrauterine insemination: analysis of outcomes of 9963 consecutive cycles. Am J Obstet Gynecol. 1999;180:1522-34.

3.

Merviel P, Heraud MH, Grenier N, Lourdel E, Sanguinet P, Copin H. Predictive factors for pregnancy after intrauterine insemination (IUI): An analysis of 1038 cycles and a review of the literature. Fertil Steril. 2010;93(1):79-88.

4.

Costello MF. Systematic review of the treatment of ovulatory infertility with clomiphene citrate and intrauterine insemination. Aust N Z J Obstet Gynaecol. 2004;44(2):93-102.

5.

Liu J, Li T-C, Wang J, Wang W, Hou Z, Liu J. The impact of ovarian stimulation on the outcome of intrauterine insemination treatment: an analysis of 8893 cycles. BJOG. 2016;123(S3):70-5.

6.

Nuojua-Huttunen S, Tomas C, Bloigu R, Tuomivaara L, Martikainen H. Intrauterine insemination treatment in subfertility: an analysis of factors affecting outcome. Hum Reprod. 1999;14(3):698-703.

7.

Farhi J, Orvieto R. Cumulative clinical pregnancy rates after $\mathrm{COH}$ and IUI in subfertile couples. Gynecol Endocrinol. 2010;26(7):500-4.

8.

Ombelet W, Vandeput H, Van de Putte G, Cox A, Janssen M, Jacobs P, Bosmans E, Steeno O, Kruger T. Intrauterine insemination after ovarian stimulation with clomiphene citrate: predictive potential of inseminating motile count and sperm morphology. Hum Reprod. 1997;12(7):1458-63.

9.

Kaser DJ, Goldman MB, Fung JL, Alper MM, Reindollar RH. When is clomiphene or gonadotropin intrauterine insemination futile? Results of the fast track and standard treatment trial and the forty and over treatment trial, two prospective randomized controlled trials. Fertil Steril. 2014;102(5):1331-7. 10.

Buyalos RP, Daneshmand S, Brzechffa PR. Basal estradiol and follicle-stimulating hormone predict fecundity in women of advanced reproductive age undergoing ovulation induction therapy. Fertil Steril. $1997 ; 68(2): 272-7$.

11.

Erdem M, Erdem A, Guler I, Atmaca S. Role of antral follicle count in controlled ovarian hyperstimulation and intrauterine insemination cycles in patients with unexplained subfertility. Fertil Steril. 2008;90(2):360-6.

12. 
Atasever M, Kalem MN, Hatýrnaz S, Hatýrnaz E, Kalem Z, Kalaylýoðlu Z. Factors affecting clinical pregnancy rates after IUI for the treatment of unexplained infertility and mild male subfertility. J Turk Ger Gynecol Assoc. 2016;17(3):134-8.

13.

Steures P, van der Steeg JW, Mol BW, Eijkemans MJ, van der Veen F, Habbema JD, Hompes PG, Bossuyt PM, Verhoeve HR, van Kasteren YM, van Dop PA. Prediction of an ongoing pregnancy after intrauterine insemination. Fertil Steril. 2004;82(1):45-51.

14.

Ibérico G, Vioque J, Ariza N, Lozano JM, Roca M, Llácer J, Bernabeu R. Analysis of factors influencing pregnancy rates in homologous intrauterine insemination. Fertil Steril. 2004;81:1308-13. 15.

Park SJ, Alvarez JR, Weiss G, Von Hagen S, Smith D, McGovern PG. Ovulatory status and follicular response predict success of clomiphene citrate-intrauterine insemination. Fertil Steril. 2007;87(5):1102-7. 16.

van Rumste MM, Custers IM, van der Veen F, van Wely M, Evers JL, Mol BW. The influence of the number of follicles on pregnancy rates in intrauterine insemination with ovarian stimulation: a meta-analysis. Hum Reprod Update. 2008;14(6):563-70.

17.

Kolibianakis EM. Endometrial thickness cannot predict ongoing pregnancy achievement in cycles stimulated with clomiphene citrate for IUI. Reprod Biomed online. 2004;8:115-8.

18.

World Health Organization. WHO Laboratory Manual for the Examination and Processing of Human Semen. 5th ed. Geneva: World Health Organization; 2010.

19.

Rotterdam ESHRE/ASRM-Sponsored PCOS Consensus Workshop Group. Revised 2003 consensus on diagnostic criteria and long-term health risks related to polycystic ovary syndrome. Fertil Steril. 2004;81(1):19-25.

20.

Honda T, Tsutsumi M, Komoda F, Tatsumi K. Acceptable pregnancy rate of unstimulated intrauterine insemination: a retrospective analysis of 17,830 cycles. Reprod Med Biol. 2015;14:27-32. 21.

Wiser A, Shalom-Paz E, Reinblatt SL, Son WY, Das M, Tulandi T, Holzer H. Ovarian stimulation and intrauterine insemination in women aged 40 years or more. Reprod Biomed Online. 2012;24(2):170-3. 22.

Dovey S, Sneeringer RM, Penzias AS. Clomiphene citrate and intrauterine insemination: analysis of more than 4100 cycles. Fertil Steril. 2008;90(6):2281-6.

23.

Haebe J, Martin J, Tekepety F, Tummon I, Shepherd K. Success of intrauterine insemination in women aged 40-42 years. Fertil Steril. 2002;78(1):29-33.

24. 
Magarelli PC, Pearlstone AC, Buyalos RP. Discrimination between chronological and ovarian age in infertile women aged 35 years and older: predicting pregnancy using basal follicle stimulating hormone, age and number of ovulation induction/intra-uterine insemination cycles. Hum Reprod. 1996;11(6):12149.

25.

van der Steeg JW, Steures P, Eijkemans MJ, Habbema JD, Hompes PG, Broekmans FJ, Bouckaert PX, Bossuyt PM, van der Veen F, Mol BW. Predictive value and clinical impact of basal follicle-stimulating hormone in subfertile, ovulatory women. J Clin Endocrinol Metab. 2007;92(6):2163-8.

26.

Speyer BE, Abramov B, Saab W, Doshi A, Sarna U, Harper JC, Serhal P. Factors influencing the outcome of intrauterine insemination (IUI): age, clinical variables and significant thresholds. J Obstet Gynaecol. 2013;33(7):697-700.

27.

Devranoðlu B, Özdamar Ö, Köle E, Eken MK, Bozdað H, Doðer E. Do younger women with elevated basal follicular stimulating hormone levels undergoing gonadotropin-stimulated intrauterine insemination cycles represent compromised reproductive outcomes? Eur J Obstet Gynecol Reprod Biol. 2016;199:1415 .

28.

Fleming R, Seifer DB, Frattarelli JL, Ruman J. Assessing ovarian response: antral follicle count versus anti-Müllerian hormone. Reprod Biomed Online. 2015;31(4):486-96.

29.

Allaire C. Endometriosis and infertility: a review. J Reprod Med. 2006;51(3):164-8.

30 .

Hughes E, Brown J, Collins JJ, Vanderkerchove P. Clomiphene citrate for unexplained subfertility in women. Cochrane Database Syst Rev. 2010. doi:10.1002/14651858.CD000057.pub2. 31.

Liu A, Zheng C, Lang J, Chen W. Letrozole versus clomiphene citrate for unexplained infertility: a systematic review and meta-analysis. J Obstet Gynaecol Res. 2014;40(5):1205-16.

32.

Veltman-Verhulst SM, Hughes E, Ayeleke RO, Cohlen BJ. Intra-uterine insemination for unexplained subfertility. Cochrane Database Syst Rev. 2016. doi:10.1002/14651858.CD001838.pub5.

33.

Cohlen B, Bijkerk A, Van der Poel S, Ombelet W. IUI: review and systematic assessment of the evidence that supports global recommendations. Hum Reprod Update. 2018;24(3):300-19.

34.

Horvath PM, Bohrer M, Shelden RM, Kemmann E. The relationship of sperm parameters to cycle fecundity in superovulated women undergoing intrauterine insemination. Fertil Steril. 1989;52(2):288-94. 35.

Wainer R, Albert M, Dorion A, Bailly M, Bergère M, Lombroso R, Gombault M, Selva J. Influence of the number of motile spermatozoa inseminated and of their morphology on the success of intrauterine 
insemination. Hum Reprod. 2004;19(9):2060-5.

36 .

Ombelet W, Dhont N, Thijssen A, Bosmans E, Kruger T. Semen quality and prediction of IUI success in male subfertility: a systematic review. Reprod Biomed Online. 2014;28(3):300-9.

37.

Dickey RP, Lu PY, Taylor SN, Rye PH. Comparison of the sperm quality necessary for successful intrauterine insemination with World Health Organization threshold values for normal sperm. Fertil Steril. 1999;71:684-9.

38.

Van Voorhis BJ, Barnett M, Sparks AE, Syrop CH, Rosenthal G, Dawson J. Effect of the total motile sperm count on the efficacy and cost-effectiveness of intrauterine insemination and in vitro fertilization. Fertil Steril. 2001;75(4):661-8.

39.

Miller DC, Smith GD, Randolph JF, Christman GM, Smith YR. Processed total motile sperm count correlates with pregnancy outcome after intra-uterine insemination. Urology. 2002;60:497-501. 40 .

Cissen M, Bensdorp A, Cohlen BJ, Repping S, de Bruin JP, van Wely M. Assisted reproductive technologies for male subfertility. Cochrane Database Syst Rev. 2016. doi:10.1002/14651858.CD000360.pub5. 41.

Bensdorp AJ, Tjon-Kon-Fat RI, Bossuyt PM, Koks CA, Oosterhuis GJ, Hoek A, Hompes PG, Broekmans FJ, Verhoeve HR, de Bruin JP, van Golde R, Repping S, Cohlen BJ, Lambers MD, van Bommel PF, Slappendel E, Perquin D, Smeenk JM, Pelinck MJ, Gianotten J, Hoozemans DA, Maas JW, Eijkemans MJ, van der Veen F, Mol BW, van Wely M. Prevention of multiple pregnancies in couples with unexplained or mild male subfertility: randomised controlled trial of in vitro fertilization with single embryo transfer or in vitro fertilization in modified natural cycle compared with intrauterine insemination with controlled ovarian hyperstimulation. BMJ. 2015;350:g7771.

42.

Goverde AJ, McDonnell J, Vermeiden JP, Schats R, Rutten FF, Schoemaker J. Intrauterine insemination or in-vitro fertilization in idiopathic subfertility and male subfertility: a randomised trial and costeffectiveness analysis. Lancet. 2000;355:13-8.

43.

Weiss NS, Kostova E, Nahuis M, Mol BWJ, van der Veen F, van Wely M. Gonadotrophins for ovulation induction in women with polycystic ovary syndrome. Cochrane Database Syst Rev. 2019. doi:10.1002/14651858.CD010290.pub3.

44.

Peeraer K, Debrock S, De Loecker P, Tomassetti C, Laenen A, Welkenhuysen M, Meeuwis L, Pelckmans S, Mol BW, Spiessens C, De Neubourg D, D'Hooghe TM. Low-dose human menopausal gonadotrophin versus clomiphene citrate in subfertile couples treated with intrauterine insemination: a randomized controlled trial. Hum Reprod. 2015;30(5):1079-88.

45 . 
Roque M, Tostes AC, Valle M, Sampaio M, Geber S. Letrozole versus clomiphene citrate in polycystic ovary syndrome: systematic review and meta-analysis. Gynecol Endocrinol. 2015;31(12):917-21. 46.

Franik S, Eltrop SM, Kremer JA, Kiesel L, Farquhar C. Aromatase inhibitors (letrozole) for subfertile women with polycystic ovary syndrome. Cochrane Database Syst Rev. 2018.

doi:10.1002/14651858.CD010287.pub3.

47.

Pourali L, Ayati S, Tavakolizadeh S, Soleimani H, Teimouri Sani F. Clomiphene citrate versus letrozole with gonadotropins in intrauterine insemination cycles: A randomized trial. Int J Reprod Biomed (Yazd). 2017;15(1):49-54.

48.

Dickey RP, Taylor SN, Lu PY, Sartop B, Rye P, Pyrzak R. Effect of diagnoses, age, sperm quality, and number of preovulatory follicles on the outcome of multiple cycles of clomiphene citrate intrauterine insemination. Fertil Steril. 2002;78:1088-95.

49.

National Institute for Health and Care Excellence. Fertility: assessment and treatment for people with fertility problems. London: NICE. 2013. https://www.ncbi.nlm.nih.gov/books/NBK327783. Accessed 23 Jun 2019.

50.

Dickey RP, Olar TT, Taylor SN, Curole DN, Matulich EM. Relationship of endometrial thickness and pattern to fecundity in ovulation induction cycles: effect of clomiphene citrate alone and with human menopausal gonadotropin. Fertil Steril. 1993;59(4):756-60.

51.

Liu Y, Ye XY, Chan C. The association between endometrial thickness and pregnancy outcome in gonadotropin-stimulated intrauterine insemination cycles. Reprod Biol Endocrinol. 2019;17:14. 52.

Weiss NS, van Vliet MN, Limpens J, Hompes PGA, Lambalk CB, Mochtar MH, van der Veen F, Mol BWJ, van Wely M. Endometrial thickness in women undergoing IUI with ovarian stimulation. How thick is too thin? A systematic review and meta-analysis. Hum Reprod. 2017;32(5):1009-18.

53.

Zollner U, Neumann C, Zollner KP. Probability of success of conservative treatment of infertility: exact timing as an important prognostic factor. J Reprod Med. 2013;58(5-6):205-11.

54.

Aboulghar M, Mansour R, Serour G, Abdrazek A, Amin Y, Rhodes C. Controlled ovarian hyperstimulation and intrauterine insemination for treatment of unexplained infertility should be limited to a maximum of three trials. Fertil Steril. 2001;75(1):88-91.

55.

Agarwal SK, Buyalos RP. Clomiphene citrate with intrauterine insemination: is it effective therapy in women above the age of 35 years? Fertil Steril. 1996;65(4):759-63. 
Figures

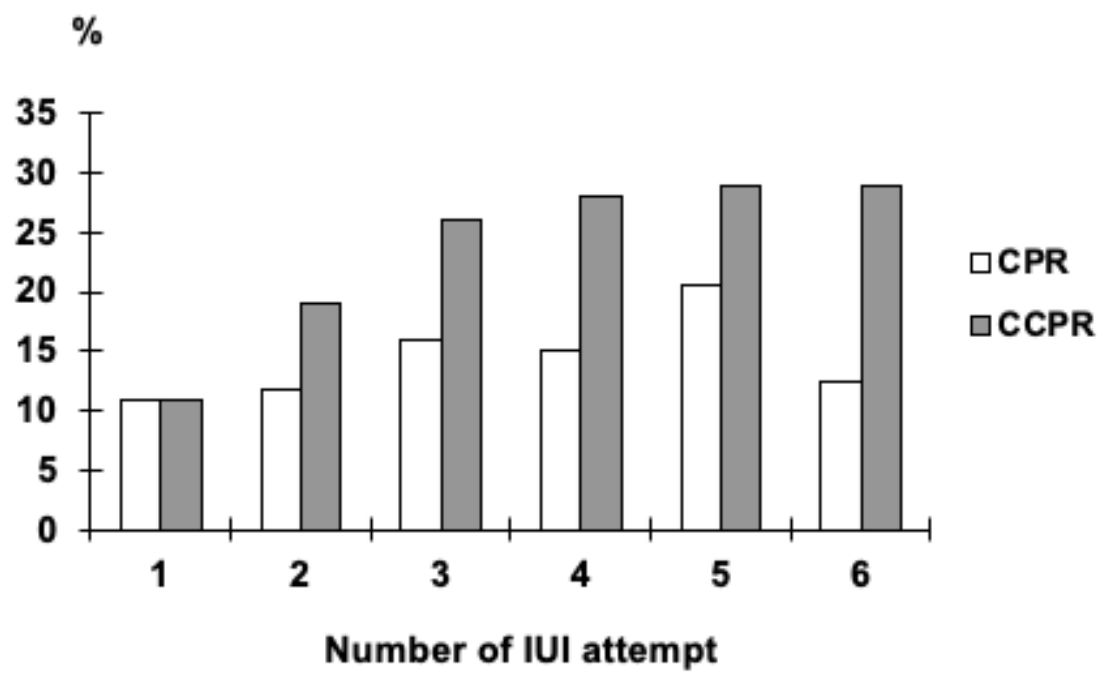

Figure 1. Clinical pregnancy rate and cumulative clinical pregnancy rate according to IUI attempt

Figure 1 